\title{
Ensino de conceitos químicos em um enfoque CTS a partir de saberes populares
}

\section{Teaching chemical concepts in a STS approach from popular knowledge}

\author{
Ricardo Luiz Zanotto $^{1}$ • Rosemari Monteiro Castilho Foggiatto Silveira ${ }^{2}$. \\ Elenise Sauer ${ }^{2}$
}

\begin{abstract}
Resumo: O presente artigo objetiva apresentar resultados de um estudo realizado sobre a utilização de saberes populares como ponto de partida para o ensino de conceitos químicos, articulando os diversos saberes sob o enfoque CTS. O trabalho foi realizado com 30 alunos da $3^{a}$ série do ensino médio de um colégio da rede estadual de ensino, da região sul do Paraná, Brasil. A abordagem metodológica foi a qualitativa, de natureza interpretativa, com observação participante. A coleta de dados se deu por meio de questionários, apresentação e discussão dos resultados das pesquisas bibliográficas, elaboração e análise de mapas conceituais, produção de infográficos (historinhas). A pesquisa demonstrou que a utilização dos saberes populares se constituiu num fator motivador e de apoio para a aprendizagem, possibilitando a contextualização dos conteúdos, tornando o ensino de Química mais atraente e significativo, facilitando, dessa maneira, a criação de estruturas cognitivas e mudanças de perfil conceitual.
\end{abstract}

Palavras-chave: Ensino de química. Ensino médio. CTS. Saber popular.

\begin{abstract}
This article presents a general objective to demonstrate the possibility of using popular knowledge as a starting point for teaching chemical concepts, using the diverse knowledge of the STS approach. The study was conducted with 30 students of the 3 rd year of a state high school, in the southern region of Paraná state, in Brazil. The methodological approach was qualitative, interpretative in nature, and used participant observation. Data collection was through questionnaires, presentation and discussion of the results of bibliographic research, preparation and analysis of conceptual maps, and infographics production (stories). The research has shown that the use of popular knowledge constituted a motivating factor and support for learning, enabling the contextualization of content, making chemistry education more attractive and meaningful, thus facilitating the creation of cognitive structures and conceptual profile change.
\end{abstract}

Keywords: Chemistry teaching. High School. STS. Popular knowledge.

\footnotetext{
${ }^{1}$ Secretaria de Estado da Educação do Estado do Paraná, Curitiba, PR, Brasil. E-mail: < faragozanotto@ibest. com.br>

${ }^{2}$ Universidade Tecnológica Federal do Paraná, Ponta Grossa, PR, Brasil.
} 


\section{Introdução}

Enquanto campo de conhecimento, a Química possibilita expandir a concepção da natureza e suas transformações, bem como, compreender as relações dos avanços científicos, tecnológicos e suas implicações na sociedade. Sendo assim, entende-se que o conhecimento químico é necessário para que o cidadão possa agir frente a múltiplos eventos do contexto em que se encontra inserido, podendo modificar seu entorno.

Em decorrência disso, percebe-se que muitos professores de Química buscam alternativas para relacionar os conceitos dos componentes curriculares aos saberes informais, viabilizando sua utilização pelos alunos na interpretação de situações reais do cotidiano.

Uma das possibilidades de articulação dos saberes consiste em trabalhar a inclusão de temas sociais na construção de conceitos científicos, promovendo mudanças conceituais e, contribuindo para a Alfabetização Científica e Tecnológica (ACT). Dessa forma, a abordagem dos saberes populares permite ao professor re(descobrir) e re(construir) conhecimentos necessários a uma alfabetização científica e tecnológica (CHASSOT, 2006).

Este artigo objetiva apresentar um estudo que utilizou saberes populares como ponto de partida para o ensino de conceitos químicos, embasado no estudo de Chassot sobre alfabetização científica, em Mortimer na mudança de perfil conceitual e mapas conceituais (MOREIRA; MASINI, 2010) como recurso de avaliação diagnóstica do processo de ensino e aprendizagem, numa perspectiva Ciência, Tecnologia e Sociedade (CTS) no ensino de química.

\section{Ensino de química x CTS x saberes populares}

No contexto de sala de aula, observa-se que há uma dissonância entre o currículo de Química e o cotidiano que o educando vivencia em relação às inovações científicas e tecnológicas. E, de acordo com Pinheiro, Silveira e Bazzo (2007), cabe ao professor oportunizar reflexões que propiciem uma alfabetização científica e tecnológica imprescindível para a compreensão da inter-relação entre a CTS, necessária ao desenvolvimento de competências para o exercício da cidadania.

A abordagem dos conteúdos num enfoque CTS é comentada nos documentos oficiais, como nas Diretrizes Curriculares Estaduais (DCE) de Ciências (PARANÁ, 2008) e na Lei de Diretrizes e Bases (BRASIL, 2000), referindo-se à dimensão social da ciência e da tecnologia em relação às suas aplicações e aos seus impactos na sociedade contemporânea, visando formação voltada ao exercício da cidadania conforme os princípios da ACT.

Diante de tantos avanços científicos e tecnológicos, há necessidade de que professores de Química criem condições para oportunizar momentos de reflexão e discussão das interações entre CTS, propiciando uma alfabetização científica e tecnológica. Entretanto, o que se observa é que grande parte dos professores de Química ainda trata o conteúdo de forma fragmentada, distanciado do cotidiano, tornando-o vazio de significado para o aluno (FREIRE, 1980), contribuindo para a desmotivação e para a criação de obstáculos à aprendizagem do educando.

O ensino de Química pode fomentar o diálogo entre os saberes de modo a desmistificar a Química como área de estudo somente de cientistas ou de pessoas com inteligência elevada que utilizam temas sociocientíficos controversos. Assim, valorizar os saberes populares é uma 
forma de despertar o interesse pela disciplina, a partir de situações significativas do contexto do educando, minimizando dificuldades decorrentes da ênfase na memorização de fórmulas e classificações. Portanto, com a valorização do saber do aluno, cria-se a possibilidade de conduzi-lo à percepção de que a Química e seus avanços fazem parte do seu cotidiano, implicando na redefinição no modo de ensinar (CHASSOT, 2006).

De acordo com Bernardelli (2004, p. 2), muitos alunos têm dificuldades de relacionar os conteúdos de Química às situações do dia a dia, à tradição cultural e à mídia. Sendo assim, entende-se que a utilização de conhecimentos populares em um enfoque CTS pode contribuir para a construção do conhecimento com mudança de perfil conceitual, conforme proposta de Mortimer (1996), fundamentada em características do construtivismo e da visão filosófica de Bachelard, em que o desenvolvimento gradual de conceitos não ocorre abandonando-se os antigos, mas, promove-se um novo nível de racionalização.

Nessa linha de pensamento é importante considerar que o processo de construção do conhecimento é influenciado por uma série de experiências individuais e sociais, a partir de evidências de que a aprendizagem dos alunos deve-se, em parte, ao conhecimento prévio de algo (HEWSON, 1989). Entretanto, ao abordar conceitos químicos a partir de saberes populares existe a premissa de que o professor saiba como conduzir o processo, porém, muitas vezes, essas ideias podem ser equivocadas, obstaculizando a cientificidade, conforme Bachelard (2008, p. 19): "Hábitos intelectuais que foram úteis e sadios podem, com o tempo, entravar a pesquisa".

Portanto, compete ao professor utilizar os saberes populares como conhecimentos prévios para o ancoramento dos novos conceitos, ou, na visão de Mortimer (1996), mudar de perfil conceitual. Dessa forma, existe a possibilidade de construir o conhecimento e a mudança de perfil conceitual sem haver conflito entre os saberes populares e o conhecimento elaborado (CHASSOT, 2006).

\section{Abordagem metodológica}

A abordagem metodológica adotada neste trabalho foi qualitativa, de natureza interpretativa, com observação participante. Participaram do estudo 30 alunos da $3^{\text {a }}$ série do ensino médio, de um colégio da rede estadual de ensino, da região sul do Paraná. A coleta de dados ocorreu no segundo semestre de 2013, totalizando 40 horas/aula, distribuídas em 6 momentos pedagógicos.

No primeiro momento pedagógico solicitou-se aos alunos que fizessem uma pesquisa junto à comunidade local sobre as principais crenças (saberes populares) que, na opinião deles, abordassem conceitos químicos.

No segundo momento, os alunos apresentaram para a turma os resultados da pesquisa realizada, constituída por uma lista dos saberes populares: "coca cola pode desentupir pia"; "cebola é utilizada em machucados para não arruinar ferimentos"; "o limão pode afinar o sangue e, portanto, pode ser usado para desentupir veias"; "em queimaduras deve ser utilizada a pasta de dente"; "o bugreiro ${ }^{3}$ causa alergias em algumas pessoas e em outras, não"; "pode se carregar

\footnotetext{
${ }^{3}$ Bugreiro: nome popular da árvore cujo nome científico é Lithraea brasiliensis (GOMES et al., 2013).
} 
pilha colocando ela na geladeira"; "quando dói machucado antigo é sinal de chuva"; "celular causa câncer"; "vinagre acaba com o chulé"; "água imantada faz bem para a saúde"; "prego na comida combate anemia"; "coca cola enfraquece os ossos"; "cebola ajuda na prevenção do câncer de mama".

No terceiro momento, após discussões, os alunos em consenso escolheram quatro dos saberes populares elencados na pesquisa, sendo que, neste artigo, são apresentados os resultados obtidos a partir do mito: "cebola é utilizada em machucados para não arruinar ferimentos".

No quarto momento realizou-se um levantamento dos conhecimentos prévios por meio de questionário, visando à construção do saber elaborado e, na análise dos dados, os nomes dos alunos foram codificados por letras seguidas de números (A1, A2, A3...).

No quinto momento foi realizada a etapa em que os alunos, com o auxílio de livros, periódicos, internet e mediação do professor, buscaram informações para desvendar o "mito da cebola". Após a discussão partiram para a construção de conceitos com vistas à mudança de perfil conceitual.

No sexto momento, os alunos distribuídos em equipes sugeriram e, em seguida, elaboraram materiais, na forma de mapas conceituais e infográficos (historinhas).

A análise dos dados se deu após a avaliação das respostas ao questionário e dos materiais desenvolvidos pelos alunos que, separados por unidades de significados, donde observadas as concordâncias e discordâncias dos dados, emergiram 3 categorias de análise: (1) o mito da cebola: concepções iniciais dos alunos; (2) desmistificando quimicamente e; (3) produção realizada pelos alunos: mudança do perfil conceitual.

\section{Resultados e Discussão}

\section{O mito da cebola: concepções iniciais dos alunos}

Nas respostas à questão: “O uso da cebola é indicado como tratamento tópico para não infeccionar ferimentos". Mito ou verdade? Por quê?

Verificou-se que $64 \%$ consideraram verdade o uso tópico da cebola em ferimentos, e $36 \%$ dos estudantes afirmaram ser mito. Assim, de acordo com as respostas obtidas, foram reunidas as mais significativas em categorias, conforme representação na Tabela 1.

Tabela 1. Uso tópico da cebola em ferimentos na percepção dos alunos

\begin{tabular}{lc}
\hline \multicolumn{1}{c}{ Categoria } & Percentual \\
\hline Antibiótico natural & $40 \%$ \\
Presença de um ácido & $24 \%$ \\
Prejudicial ao ferimento & $08 \%$ \\
Não previne infecções & $28 \%$ \\
\hline
\end{tabular}

Fonte: elaborada pelos autores a partir das respostas dos alunos. 
Quando os alunos apontaram que a cebola possui “antibióticos naturais", percebe-se uma linguagem de enculturação vivenciada no seu contexto, oriunda dos saberes populares relacionados aos aspectos intuitivos e empíricos, os quais podem ser ampliados no sentido de favorecer o conhecimento científico (CHASSOT, 2006). Considerando o conjunto das respostas elencadas, observou-se haver multiplicidade de ideias pré-existentes dos educandos a respeito do uso da cebola, úteis à construção de novos conceitos.

Na resposta à questão: "Você ou alguém do seu convívio já utilizou a cebola em ferimentos? Um total de $56 \%$ dos alunos afirmou já terem feito uso, ou de conhecerem alguém que já fez uso da cebola no tratamento de infecções, conforme observado nas respostas: "Quando pisei em um prego, um [...] mandou eu colocar a cebola para esquentar e colocar no ferimento para não infeccionar" (A1); e, ainda, "Certa vez, pisei em um prego, minha mãe partiu uma cebola e colocou no ferimento, porque minha avó indicou” (A9).

No entanto, $41 \%$ dos estudantes responderam que nunca usaram a cebola com a finalidade de curar ferimentos tópicos, e não conhecerem alguém que a tenha utilizado com essa finalidade. E, uma minoria (3\%) não opinou. Por meio das respostas dos alunos, tornaram-se evidentes os aspectos marcantes da transmissão dos saberes entre os indivíduos de uma comunidade, fruto dos conhecimentos adquiridos por grupos de classes, sobre eventos do cotidiano (LOPES, 1993).

Nas respostas à questão: "Em sua opinião, o que levou as pessoas a utilizarem a cebola nos ferimentos?" A maioria $(87,7 \%)$ associou o uso da cebola em ferimentos à indicação de pessoas mais antigas da comunidade; os demais (12,3\%) disseram que se deve à falta de medicamentos para alívio da dor. Foi possível perceber nas respostas dos alunos, que os vínculos culturais são muito fortes nas famílias e que os saberes transitam entre as gerações.

Diante da questão: "O que você acha que existe na cebola que possa prevenir infecções?” A maior parte (68\%) dos estudantes fez alusão a determinado tipo de ácido que, em contato com o ferimento, promove uma reação química, "puxando a infecção" e aliviando o desconforto local. Além disso, associou o cheiro da cebola à presença do enxofre em sua composição. Observou-se que $14 \%$ dos alunos acreditavam que a parte líquida da cebola deveria apresentar propriedades bactericidas, enquanto $18 \%$ responderam que não acontece nada, pois a cebola não é medicamento, portanto, não possui nenhuma substância com capacidade de prevenir infecções.

Ao serem questionados: "Se essa crença for verdadeira por que você acha que as indústrias farmacêuticas não investem nisso?” As respostas dos alunos foram estratificadas conforme mostra a Tabela 2 , onde $20 \%$ responderam a opção de redução dos lucros da indústria farmacêutica e 16,7\% optaram pela dificuldade de obtenção de uma substância farmacologicamente ativa, indicando uma percepção das implicações científicas e tecnológicas relacionadas à indústria em questão e suas implicações na sociedade.

Entretanto, 53,3\% dos participantes da pesquisa sinalizaram que a não constatação científica das propriedades da cebola seria um entrave para seu uso industrializado, assim, evidenciou-se o enfoque contextual sugerido, paradoxalmente, entre o conhecimento científico tido como verdadeiro, desprovido de falhas, absoluto em seu caráter e o conhecimento comum carente de comprovação. 
Tabela 2. Percepções dos alunos sobre o investimento das indústrias farmacêuticas na pesquisa dos princípios ativos da cebola

\begin{tabular}{lc}
\hline \multicolumn{1}{c}{ Categoria } & Percentual \\
\hline Falta de comprovação científica & $53,3 \%$ \\
Redução dos lucros da indústria farmacêutica & $20,0 \%$ \\
Dificuldade de obtenção de uma substância & $16,7 \%$ \\
farmacologicamente ativa & \\
\hline
\end{tabular}

Fonte: elaborada pelos autores a partir das respostas dos alunos.

Com certeza não se pode lançar no mercado produtos com finalidades medicinais sem um estudo científico criterioso. Todavia, se forem considerados apenas aspectos lucrativos, e se os laboratórios seguirem um modelo social centrado em uma cultura de controle da dominação e dependência, jamais haverá pesquisas visando propósitos mais nobres de humanização.

Conforme as informações levantadas, visualizou-se a possibilidade de transpor as fronteiras do conhecimento informal, ou seja, dos saberes transitados entre as gerações, alcançados conforme as aptidões cognitivas individuais, desde que sejam enfatizadas suas relações com os saberes formais, com base em um aprofundamento progressivo da racionalização (AMARAL; MORTIMER, 2011).

Os dados obtidos nesse momento da pesquisa possibilitaram o diagnóstico dos saberes oriundos do senso comum e, a partir deles, abordar os conceitos sobre as funções orgânicas aminas, fenol, éter, compostos sulfurados, haletos orgânicos, e relações biológicas, físicas e sociais envolvidas no processo de elaboração e construção do saber. Por meio dessa atividade foi possível valorizar os saberes populares da comunidade em que a escola está inserida e, segundo Chassot (2006), esse tipo de encaminhamento metodológico constitui-se como base para a ACT e para demonstrar que a Ciência não está dissociada do cotidiano.

O resgate desse saber popular da comunidade propiciou momentos de discussão e conflitos, os quais foram utilizados para o desenvolvimento de perfis conceituais como uma condição para a construção de conceitos químicos (MORTIMER; MACHADO, 2011).

\section{Desmistificando quimicamente}

Os alunos, a partir de pesquisas, apresentaram e discutiram química e biologicamente as propriedades das substâncias presentes na cebola, demonstrando que existem substâncias voláteis como óxido de enxofre, responsáveis pelo aroma característico deste vegetal, oriundo do tiossulfato acumulado nos vacúolos. Na experimentação do corte de uma cebola, observaram que os vacúolos são rompidos com liberação de enzimas que promovem a formação de compostos sulfurados como o ácido 1-propenilsulfênico (Figura 1), responsável pelo fator lacrimogêneo (CHEMELLO, 2005). 
Figura 1. Fórmula estrutural da molécula

do ácido 1-propenilsulfênico
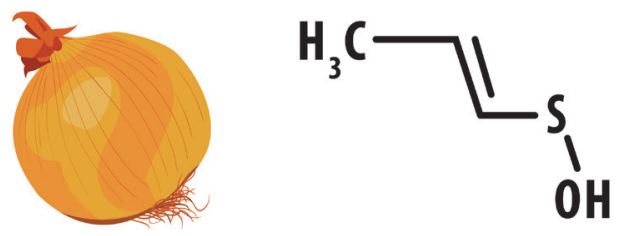

Fonte: elaborada pelos autores

Nesse momento, o docente abordou que os compostos organossulfurados contêm pelo menos uma ligação covalente entre carbono e enxofre (Figura 1), sendo frequentemente associados a odores, e que são abundantes na natureza dado que o enxofre é essencial à vida. Continuando a abordagem com cadeias carbônicas, e estudo de diferentes funções orgânicas, os alunos acrescentaram que a cebola também contém uma substância chamada alicina (2-propeno-1-ácido sulfinotióico), a qual de acordo com Magalhães (2007) destrói grupos tiólicos (-SH) essenciais à proliferação bacteriana, apresentando propriedades bacteriostáticas e bactericidas sobre uma diversidade de microrganismos Gram positivos e negativos.

Apresentaram que as propriedades fitoterápicas da alicina (2-propeno-1-ácido sulfinotióico) constituem fonte de pesquisa conduzida com isolamento de moléculas voltadas ao tratamento de determinadas patologias (VENÂNCIO, 2010). É considerado um importante antimicrobiano (PARRA, 2011), com ação de inibição do desenvolvimento bacteriano observado na sua forma pura ao ligar-se à enzima álcool desidrogenase presente em microrganismos patogênicos (ALVARENGA et al., 2004).

Evidenciaram que a cebola contém sais minerais, destacando o ferro, cálcio, potássio, selênio e magnésio. Discutiram: que o ferro presente em vegetais está na forma não heme; suas características físicas e químicas; a presença na crosta terrestre; sua importância tecnológica, cuja principal aplicação é na fabricação do aço; a classificação e propriedades periódicas; e, a suscetibilidade magnética, que é constituinte da hemoglobina, pigmento das hemácias que transporta oxigênio na respiração (RUSSEL, 1994).

Apresentaram informações levantadas sobre os minerais Cálcio, Potássio, Selênio e Magnésio, presentes na cebola à semelhança das levantadas sobre o ferro, evidenciando suas propriedades físicas, químicas e suas aplicações tecnológicas, assim como a importância e suas correlações nos sistemas biológicos em geral e no corpo humano.

Como exemplos de informações enfatizadas pelos alunos, podem ser citadas: a importância do Cálcio na constituição dos ossos e dentes, na regulação dos batimentos cardíacos e na coagulação do sangue; a função fundamental do Potássio na fisiologia dos músculos, e sua utilização em vegetais como fertilizantes; a aplicação do Selênio, em aparelhos células fotoelétricos, câmaras de televisão, em razão da condutividade elétrica que varia com a luz, além da importância para ossos e dentes, e que sua deficiência no organismo é responsável por distúrbios 
musculares, depressão e doenças cardíacas; e, a utilização do Magnésio nos fogos de artifício e em lâmpadas de flash, e que sua falta no organismo provoca efeitos semelhantes ao do alcoolismo agudo, tendo importante papel na síntese do DNA e RNA (PERUZZO; CANTO, 2003).

Os alunos levantaram nas pesquisas sobre a cebola, conceitos químicos de várias fases da estrutura curricular atual e anterior, exercitando a consolidação e construção do conhecimento simultaneamente. Entretanto, em nenhum momento citaram os flavonoides. Assim, ocorreu a interferência docente apresentando a eles que a cebola possui um flavonoide natural conhecido como quercetina (composto fenólico da classe dos polifenóis) (Figura 2), que possui propriedades farmacológicas anti-inflamatórias e anticarcinogênicas (atuando no sistema imunológico). Aqui fica evidente que apesar dos conhecimentos prévios dos educandos serem importantes no processo, devem ser constantemente aprimorados, para que não se constituam num entrave na construção do conhecimento científico (BACHELARD, 2008).

Figura 2. Fórmula estrutural da molécula de Quercetina

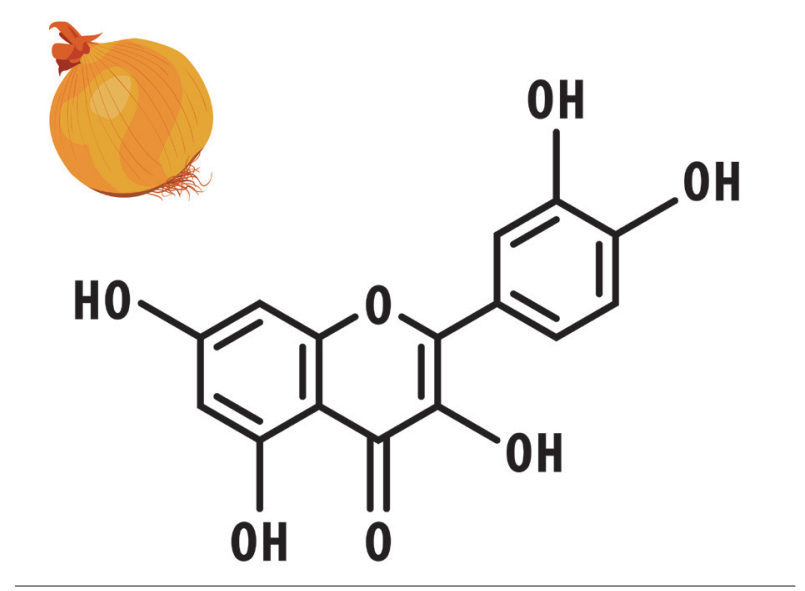

Fonte: elaborada pelos autores

Foi esclarecido aos alunos que polifenólicos, como a Quercetina (3,3',4',5,7-Pentahydroxyflavon), são substâncias químicas presentes em determinados vegetais, com atividade antimicrobiana, antiviral, antifúngica e anti-inflamatória, além de serem responsáveis pela adstringência e amargor de alimentos e bebidas. É excelente agente sequestrador de radicais livres e íons metálicos, efeitos da posição e do número de grupamentos $(-\mathrm{OH})$ presentes na molécula, característica que lhe confere relevante atividade antioxidante (MUNIZ, 2007).

Também foi enfatizado que a cebola contém flavonoides (polifenólicos) e sulfóxidos de cisteína (organossulfurados), com comprovado benefício à saúde (MUNIZ, 2007). Em geral, que os primeiros apresentam propriedades cardiovasculares, anti-inflamatórias e antibacterianas, enquanto que os compostos organossulfurados têm propriedades anticarcinogênicas, inibidoras de tromboses, ação antiasmática e efeito antibiótico (CARVALHO; MACHADO, 2004). E que, a substância quercetina tem ação anti-inflamatória, atuando na modulação de enzimas 
no metabolismo do ácido araquidônico (ácido graxo essencial), inibindo citocinas (substâncias necessárias para a resposta inflamatória-base nitrogenada) e do óxido nítrico (NO) por cancelamento da ativação de determinadas proteínas (WILLAIN FILHO, 2005).

Analisando a afirmação central, "cebola é utilizada em machucados para não arruinar", após as pesquisas de estudos dos seus componentes e seus efeitos no organismo, constatou-se que determinadas substâncias da cebola têm propriedades antimicrobianas e anti-inflamatórias comprovadas, portanto o conhecimento popular é coerente.

\section{Produção realizada pelos alunos: mudança do perfil conceitual}

Ao longo da realização do estudo, os alunos tiveram a oportunidade de rever seus conhecimentos iniciais sobre os temas abordados e, aos poucos, mudar o perfil conceitual, sem haver imposição da substituição dos saberes populares pelo conhecimento científico (CHASSOT, 2006). Ressalta-se que, em nenhum momento o professor sobrepôs o conhecimento científico ao senso comum, mas, os próprios alunos, aos poucos, foram construindo os conceitos, conforme se observa nos exemplos de mapas conceituais (Figura 3) e infográficos (Figura 4).

No mapa conceitual elaborado pelos alunos (Figura 3) percebe-se claramente a mudança de perfil conceitual e a construção de novos conceitos químicos, a partir dos conhecimentos prévios do "mito da cebola".

No infográfico, na historinha da cebola (Figura 4), observou-se que no conteúdo abordado pelos alunos houve evolução de conceitos químicos tanto quanto biológicos, em relação às respostas apresentadas no início do processo, reforçando que a produção de infográficos (historinhas) pelos alunos, pode contribuir para o desenvolvimento do pensamento crítico, organização das informações e interesse no aprofundamento dos conceitos elaborados, conforme Strack et al. (2010).

Foi possível perceber na análise das diferentes atividades que os alunos tiveram avanços na aprendizagem de conceitos científicos, a partir dos saberes populares e, que houve alfabetização científica e tecnológica, quando os alunos relacionaram a utilização da cebola com benefícios à saúde, bem como nas analogias entre os componentes químicos da cebola e sua utilização na indústria farmacêutica. Essas relações e analogias mostraram a reflexão dos impactos na saúde e economia da sociedade contemporânea, evidenciando as relações sociais da ciência e da tecnologia.

Verificou-se também que, após o processo envolvendo a tríade professor-alunos- conteúdo (SCHNETZLER, 1992), houve mudança conceitual em relação aos conceitos anteriores, nos conceitos químicos teóricos e práticos, evidenciando a importância do ensino com estratégias didáticas que possibilitem aos alunos construírem ativamente o conhecimento. A construção do conhecimento científico a partir da realidade do educando, na contextualização a partir de temas sociais, propiciou o desenvolvimento da capacidade de participação, de julgamento e de tomada de decisão na resolução de problemas, conforme Mortimer (1992), Chassot (2006) e Freire (1980).

O trabalho desenvolvido valorizou os saberes populares para, a partir daí, construir o conhecimento científico. O enfoque nas reflexões CTS possibilitou a participação ativa dos estudantes na edificação de atitudes, conforme Silveira e Bazzo (2009) e, sobretudo, conduziu a percepção de que não existe conhecimento pronto, e sim, a construção permanente do saber. 
Figura 3. Mapa conceitual sobre a cebola

Mapa conceitual elaborado pela equipe de alunos

Assunto: Cebola

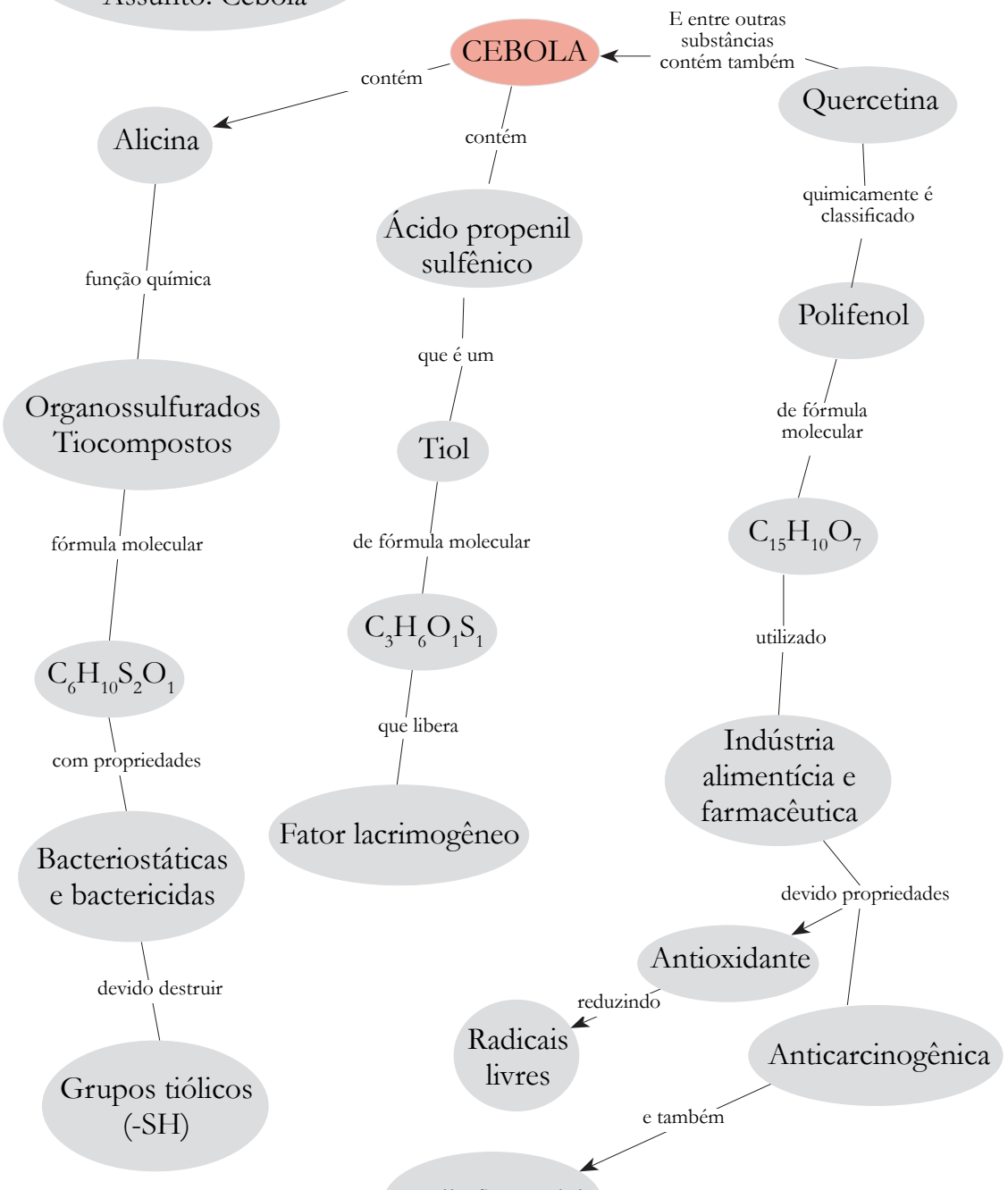

Antiinflamatória

Fonte: elaborada pelos autores 
Figura 4. Historinha chorando com cebolas

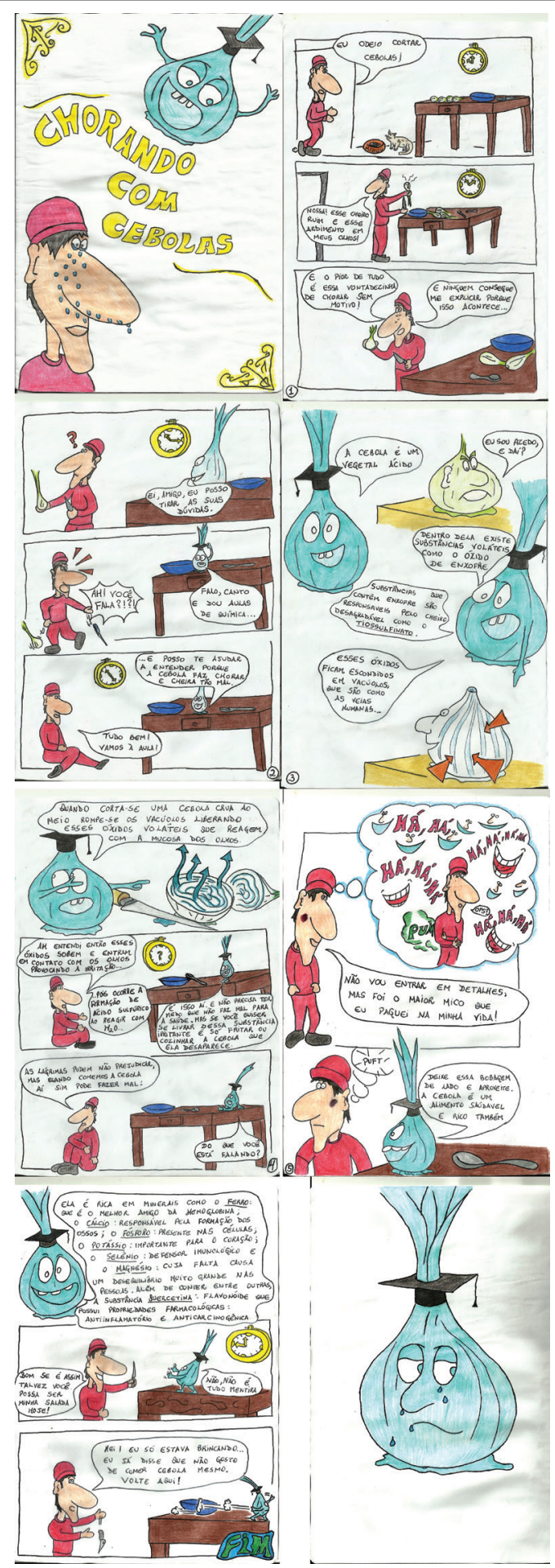

Fonte: elaborada pelos autores a partir do trabalho dos alunos. 


\section{Conclusão}

Com o objetivo de minimizar a desmotivação e o desinteresse pela disciplina de Química distanciada da realidade, levantou-se na comunidade escolar, saberes populares que envolvem conceitos químicos, especialmente aqueles relacionados às funções orgânicas, valorizando-os e transpondo-os para o conhecimento científico, por meio do enfoque CTS.

Foi possível abordar o conteúdo de funções orgânicas de forma contextualizada, pautado em situações reais da vivência dos alunos com enfoque CTS, evidenciando as relações conceituais entre os saberes populares vinculados e os saberes escolares. Reforça-se assim, que o compromisso de buscar maneiras de abordar os conhecimentos oriundos da comunidade de sua escola e de conduzi-los para a sala de aula é de competência do professor.

Foi possível constatar transições de perfil conceitual, por meio da produção de mapas conceituais, infográficos interativos e historinhas construídas pelos educandos, enfatizando o crescente nível de racionalização e a percepção das relações sociais decorrentes dos avanços da Ciência e Tecnologia, ausentes nos primeiros materiais produzidos pelos alunos.

Sendo assim, pode-se afirmar que muitos saberes populares transitados nas comunidades, algumas vezes considerados pelo professor como obstáculos à aprendizagem, podem ser utilizados na abordagem de conceitos químicos, com enfoque CTS, contribuindo para uma construção gradativa do conhecimento com vistas à mudança de perfil conceitual no ensino de Química, tornando-o mais atraente e significativo, e, possibilitando ao discente a percepção de relações sociais com o tema em estudo.

\section{Referências}

ALVARENGA, L. C. et al. Alteração da carga de carrapatos de bovinos sob a ingestão de diferentes níveis do resíduo do beneficiamento do alho. Ciência e Agrotecnologia, Lavras, v. 28, n. 4, p. 906-912, 2004. Disponível em: < http://dx.doi.org/10.1590/S141370542004000400025>. Acesso em: 15 jun. 2016.

AMARAL, E. M. R.; MORTIMER, E. F. Uma metodologia para análise da dinâmica entre zonas de um perfil conceitual no discurso de sala de aula. Ijuí: Ed. Unijuí, 2011.

BACHELARD, G. A formação do espírito científico. 8. ed. Rio de Janeiro: Contraponto, 2008.

BERNARDELLI, M. S. Encantar para ensinar: um procedimento alternativo para o ensino de química. In: CONGRESSO BRASILEIRO DE PSICOTERAPIAS CORPORAIS, 9., 2004, Foz do Iguaçu. Anais... [S.1.]: Centro Reichiano, 2004. 1 CD-ROM.

BRASIL. Ministério da Educação. Parâmetros curriculares nacionais do ensino médio: bases legais. Brasília, 2000. 
CARVALHO, P. G. B.; MACHADO, C. M. M. Sistema de produção de cebola (Allium cepa L.). Brasília: Embrapa Hortaliças, 2004. (Série características nutricionais e funcionais, $5)$.

CHASSOT, A. Alfabetização científica: questões e desafios para a educação. 4. ed. Ijuí: Ed. Unijuí, 2006.

CHEMELLO, E. A química na cozinha apresenta: as cebolas. Zoom, São Paulo, v. 6, n. 2, p. 1-9, 2005. Disponível em: <http//www.quimica.net/emiliano/artigos/2005jun_qnc_ cebola.pdf $>$. Acesso em: 15 jun. 2016.

FREIRE, P. Conscientização: teoria e prática da libertação. São Paulo: Moraes, 1980.

GOMES, G. C. et al. Árvores da Serra dos Tapes: guia de identificação com informações ecológicas, econômicas e culturais. Brasília: Embrapa, 2013.

HEWSON, P. W. The conditions of conceptual change in the classroom. International Journal of Science Education, Abingdon, v. 11, n. 5, p. 541-553, 1989.

LOPES, A. R. C. O currículo e a construção do conhecimento na escola: controvérsias entre conhecimento comum e conhecimento científico no ensino de ciências físicas. In: REUNIÃO ANUAL DA ASSOCIAÇÃO NACIONAL DE PÓS-GRADUAÇÃO E PESQUISA EM EDUCAÇÃO, 16., 1993, Caxambu. Anais... Caxambu: ANPED, 1993.

MAGALHÃES, L. Os alimentos contra o câncer. Petrópolis: Vozes, 2007.

MOREIRA, M. A.; MASINI, E. F. S. Aprendizagem significativa: a teoria de David Ausubel. São Paulo: Centauro, 2010.

MORTIMER, E. F. Construtivismo, mudança conceitual e ensino de ciências: para onde vamos? Investigações em Ensino de Ciências, Porto Alegre, v. 1, n. 1, p. 20-39, 1996. Disponível em: < http//www.if.ufrgs.br/public/ensino/N1/2artigo.htm>. Acesso em: 15 jun. 2016.

- Pressupostos epistemológicos para uma metodologia de ensino de química: mudança conceitual e perfil epistemológico. Química Nova, São Paulo, v. 15, n. 3, p. 242-249, 1992.

MORTIMER, E. F.; MACHADO, A. H. Química: ensino médio. São Paulo: Scipione, 2011. v. 1.

MUNIZ, L. B. Caracterização química, física e de compostos funcionais em cebolas frescas e minimamente processadas. 2007. Dissertação (Mestrado em Nutrição Humana) - Universidade de Brasília, Brasília, 2007.

PARANÁ. Secretaria de Estado da Educação. Diretrizes curriculares estaduais de química. Curitiba, 2008.

PARRA, C. L. C. Soluções de alho no controle de nematódeos gastrintestinais em bovinos jovens. 2011. 52 f. Dissertação (Mestrado em Zootecnia) - Faculdade de Zootecnia, Universidade Federal de Santa Maria, Santa Maria, 2011. 
PERUZZO, F. M.; CANTO, E. L. Química na abordagem do cotidiano. 3. ed. São Paulo: Moderna, 2003.

PINHEIRO, N. A. M.; SILVEIRA, R. M. C. F.; BAZZO, W. A. Ciência, tecnologia e sociedade: a relevância do enfoque CTS para o contexto do ensino médio. Ciência $\boldsymbol{\&}$ Educação, Bauru, v. 13, n. 1, p. 71-84, 2007. Disponível em: <http://dx.doi.org/10.1590/ S1516-73132007000100005>. Acesso em: 15 jun. 2016.

RUSSEL, J. B. Química geral. 2. ed. São Paulo: Pearson: Makron Books, 1994. v. 1.

SCHNETZLER, R. P. Construção do conhecimento e ensino de ciências. Em Aberto, Brasília, v. 11, n. 55, p. 17-22, 1992.

SILVEIRA, R. M. C. F.; BAZZO, W. A. Ciência, tecnologia e suas relações sociais: a percepção de geradores de tecnologia e suas implicações na educação tecnológica. Ciência \& Educação, Bauru, v. 15, n. 3, p. 681-694, 2009. Disponível em: < http://dx.doi. org/10.1590/S1516-73132009000300014>. Acesso em: 15 jun. 2016.

STRACK, V. et al. A infografia como recurso pedagógico no ensino em ambientes culturais. In: CONGRESSO BRASILEIRO DE PESQUISA E DESENVOLVIMENTO EM DESIGN, 9., 2010. Anais... 2010. Disponível em: <http://ebooks.pucrs.br/edipucrs/ Ebooks/Web/978-85-397-0173-5/Sumario/2.1.7.pdf>. Acesso em: 15 jan. 2015.

VENÂNCIO, P. C. Composição química e atividade antimicrobiana e de extratos à base de alho (Allium sativum e Allium tuberosum) sobre a infecção estafilocócica: estudo in vitro e in vivo, em ratos. 2010. $47 \mathrm{f}$. Tese (Doutorado em Odontologia) - Faculdade de Odontologia de Piracicaba, Universidade Estadual de Campinas, Piracicaba, 2010.

WILLAIN FILHO, A. Potencial analgésico de flavonoides: estudo do mecanismo de ação da quercetina. 2005. Dissertação (Mestrado em Ciências Farmacêuticas) - Universidade do Vale do Itajaí, Itajaí, 2005.

Artigo recebido em 02/09/15. Aceito em 05/01/2016.

Endereço para contato: Rua Monteiro Lobato, s/n, Km 04, CEP

84016-210, Ponta Grossa, PR, Brasil. 